\section{Taking the sting out of needles}

Why do doctors not do what is known to work? There would seem to be only a few possible reasons: they may be unaware of the evidence; they may disagree with the evidence; or they may accept the evidence but choose to disregard it. On p. 158 Dr Sado and Dr Deakin ${ }^{1}$ report on doctors' use of local anaesthesia for venous cannulation and find that little has changed in a decade: ${ }^{2}$ very few ward doctors routinely use local anaesthesia for cannulation, despite an abundance of evidence that it makes the procedure much more bearable (the same is true of arterial puncture, but here I focus on venous cannulation because it is so much more common). The unanimous conclusion of those who have investigated the matter is that patients and volunteers find the pain of local anaesthetic infiltration less than that of cannulation, ${ }^{3-12}$ even with cannulae as small as 20 gauge, and cannulation is not made more difficult by the procedure. ${ }^{6,9}$ Could it be that doctors accept the efficacy of local anaesthetic but do not use it because the pain of cannulation is not thought bad enough to warrant the extra hassle? My own impression from observing and talking to other doctors, supported by the findings of Sado and Deakin and others, ${ }^{1,11}$ is that this accounts for part of their reluctance - the pain of cannulation is considered regrettable but a fact of life (no pain, no gain). But another factor, as many have found, is simple ignorance: they are unaware of the evidence and nobody has ever taught them to use local anaesthesia for these procedures..$^{2,13,14}$

The observation that anaesthetists are more likely to use local anaesthetic than doctors in other specialties ${ }^{1,2,13,14}$ may reflect their central preoccupation, in clinical work, with the prevention and control of pain. They also know how much more difficult it can be to anaesthetize an anxious patient stressed by the siting of a cannula than a calm one. Another possibility is that anaesthetists are simply more familiar with local anaesthetics and therefore more comfortable using them. Or perhaps anaesthetists are less likely than others to regard the pain of cannulation as 'normal' because so many of their patients - those having elective surgery for example - are not uncomfortable to start with and are less tolerant of new pain. A parallel can be drawn with the use of spinal needles: for years it has been known that the incidence and severity of postdural puncture headache can be lessened by use of small conically tipped needles, but physicians and surgeons have been been much slower to apply this knowledge than their anaesthetic colleagues. ${ }^{15}$

Does it matter? To answer this question you merely have to ask anyone who has ever had an intravenous cannula inserted - or better still, ask a colleague to insert one in your own arm (without local, of course). Not everyone suffers severe pain, but many people do. The grateful relief of patients who, after experiencing their first pain-free cannulation, have admitted that the pain of previous cannulations has led them to fear this procedure above most others, will be familiar to anyone who routinely uses local anaesthetic. And the squirming, distressed patient who suffers cannulation with clenched teeth and tears in the eyes will be familiar to anyone who routinely does not. So yes, the pain of cannulation does matter, and since we have the ability to prevent it at low cost and with negligible risk, how can we justify not doing so? Although other manoeuvres can reduce the pain of cannulation, such as

Box 1 Method for painless injection of local anaesthetic before venous cannulation

1. Allow alcohol cleanser to dry completely

2. Draw $1 \mathrm{~mL}$ lidocaine $1 \%$ into a $2 \mathrm{~mL}$ syringe and attach a 25 gauge (orange) needle

3. Position the needle above the injection site so that its bevel is parallel to the skin

4. Firmly press the bevel flat against the skin with the thumb of the non-dominant hand, while applying firm constant pressure to the plunger of the syringe with the dominant hand. A small amount of local anaesthetic may leak out but ignore this

5. Very slowly, advance the needle (still with the bevel parallel to the skin and still with pressure applied to the plunger) until a small white bleb begins to appear in the skin. At this point, stop advancing but continue to inject slowly until the bleb grows to about $4-5 \mathrm{~mm}$

6. Further lidocaine can be slowly injected under the skin if the vein is deep; otherwise the intradermal bleb will be adequate for cannulation of a superficial vein

7. The cannula may now be advanced painlessly through the skin. 
'darting' the cannula through the skin or getting the patient to cough, ${ }^{16}$ and although other analgesics or drug delivery systems have also been shown to be effective, ${ }^{17,18}$ local anaesthetic injection is the only readily available method that allows slow, careful and painless cannulation, improving the chance of success and maintaining the patient's confidence.

Finally, for anyone still sceptical, there is a little-known way of injecting the local anaesthetic that is virtually pain-free, as the many trainees on whom I have demonstrated it over the years can personally testify. It does not rely on mixing additives with the local anaesthetic ${ }^{19}$ or having to use special needles. ${ }^{12}$ This technique (Box 1) has transformed the way I have cannulated over the past decade, and I only wish that I could remember who first described it to me, so that I could thank him or her on behalf of my patients.

\section{S M Yentis}

Chelsea and Westminster Hospital,
London, UK
E-mail: s.yentis@imperial.ac.uk

E-mail: s.yentis@imperial.ac.uk

\section{REFERENCES}

1 Sado DM, Deakin CD. Local anaesthesia for venous cannulation and arterial blood gas sampling: are doctors using it? $J$ R Soc Med 2005;98:158-60

2 Yentis SM. Use of intravenous cannulae by junior hospital doctors. Postgrad Med J 1993;69:389-91

3 Harrison N, Langham BT, Bogod DG. Appropriate use of local anaesthetic for venous cannulation. Anaesthesia 1992;47:10-12

4 Harris T, Cameron PA, Ugoni A. The use of pre-cannulation local anaesthetic and factors affecting pain perception in the emergency department setting. Emerg Med J 2001;18:175-7

5 Langham BT, Harrison DA. Local anaesthetic: does it really reduce the pain of insertion of all sizes of venous cannula. Anaesthesia 1992;47:890-1
6 Holdgate A, Wong G. Does local anaesthetic affect the success rate of intravenous cannulation? Anaesth Intens Care 1999;27:257-9

7 Van den Berg AA, Prabhu NV. Rationalizing venepuncture pain: comparison of lignocaine injection, Butterfly (21 gauge and 23 gauge) and Venflon (20 gauge). Anaesth Intens Care 1995;23:165-7

8 Speirs AF, Taylor KH, Joanes DN, Girdler NM. A randomised, double-blind, placebo-controlled, comparative study of topical skin analgesics and the anxiety and discomfort associated with venous cannulation. Br Dent J 2001;19:444-9

9 Selby IR, Bowles BJ. Analgesia for venous cannulation: a comparison of EMLA (5 minutes application), lignocaine, ethyl chloride, and nothing. J R Soc Med 1995;88:264-7

10 Nuttall GA, Barnett MR, Smith RL 2nd, Blue TK, Clark KR, Payton BW. Establishing intravenous access: a study of local anesthetic efficacy. Anesth Analg 1993;77:950-3

11 Biro P, Meier T, Cummins AS. Comparison of topical anaesthesia methods for venous cannulation in adults. Eur J Pain 1997;1:37-42

12 Prien T. Intradermal anaesthesia: comparison of several compounds. Acta Anaesth Scand 1994;38:805-7

13 O'Connor PJ, Caldicott LD. Local anaesthesia and venous cannulation. Anaesthesia 1995;50:1005

14 Paton RH. Local anaesthesia and venous cannulation. Anaesthesia 1995;50:1005-6

15 Serpell MG, Haldane GJ, Jamieson DR, Carson D. Prevention of headache after lumbar puncture: questionnaire survey of neurologists and neurosurgeons in United Kingdom. BMJ 1998;316:1709-10

16 Usichenko TI, Pavlovic D, Foellner S, Wendt M. Reducing venipuncture pain by a cough trick: a randomized crossover volunteer study. Anesth Analg 2004;98:343-5

17 Moppett IK, Szypula K, Yeoman PM. Comparison of EMLA and lidocaine iontophoresis for cannulation analgesia. Eur $J$ Anaesthesiol 2004;21:210-13

18 Lysakowski C, Dumont L, Tramer MR, Tassonyi E. A needle-free jetinjection system with lidocaine for peripheral intravenous cannula insertion: a randomized controlled trial with cost-effectiveness analysis. Anesth Analg 2003;96:215-19

19 Martin AJ. pH-adjustment and discomfort caused by the intradermal injection of lignocaine. Anaesthesia 1990;45:975-8 